\title{
Análisis espacio-temporal de los usos de suelo y sus presiones como herramienta de gestión integrada de cuencas. El caso de la microcuenca Tarariras, Maldonado, Uruguay
}

\section{Spatio-temporal analysis of environmental drivers and its pressures as a tool for whole-basin management: The case study of the Tarariras basin, Maldonado, Uruguay}

Silvera, Nicolás (1); Olivera, Fidel (1); Frachia, Rosina (1); Armand Ugón, Inés (1); Garrido Silveira, Mariana (1); Fascioli, Sofia (1); De los Santos, Paula (1); Brum Bulanti, Laura (2); García Alonso, Javier (2).

(1) Licenciatura en Gestión Ambiental, Centro Universitario Regional del Este (CURE), Universidad de la República (UdelaR).

(2) Centro Universitario Regional del Este (CURE), Universidad de la República (UdelaR), Uruguay.

Contacto: olivera.fidel6@gmail.com

RECIBIDO: $31 / 3 / 2017$ - APROBADO: 14/6/2017

\begin{abstract}
Resumen
La microcuenca del Arroyo Tarariras (Maldonado, Uruguay) abarca una diversidad de ambientes de serranías y costa con diversos valores patrimoniales, culturales y naturales. Presenta variados usos de suelo (rural y urbano) que generan distintas presiones en el ambiente. Debido a su escala y particularidades geomorfológicas, es un excelente modelo de estudio en dinámicas espaciotemporales naturales y antrópicas a nivel de cuenca. Con base en la fotointerpretación de imágenes aéreas (1966 y 2013) se analizaron los principales cambios en la cobertura del suelo, verificados mediante observación directa, y se logró un mapeo completo a nivel cuenca. Se categorizó el bosque a través de un muestreo fitosociológico y se complementó con entrevistas a informantes seleccionados y análisis de la normativa y planificación territorial prevista para la zona. Finalmente, se identificaron presiones ejercidas por distintos usos, por ejemplo, urbanización, nuevas formas de uso del espacio rural (clubes de campo), invasión de especies exóticas en bosques y cambios en el cauce del arroyo (descarga de efluentes y represas). Los abordajes a nivel de cuenca y de parámetros cualitativos y cuantitativos permitieron identificar presiones ambientales con potenciales cambios, reversibles o no en el ambiente, con miras a una gestión integrada de los socioecosistemas. Palabras clave: Gestión ambiental, fotointerpretación, fitosociología.
\end{abstract}

\begin{abstract}
The microbasin of the Tarariras creek (Maldonado, Uruguay) covers different types of environments, from hills to coastal areas, including diverse natural, cultural and national heritage values. This basin presents different land uses (rural and urban) with specific environmental pressures. Due to its small scale and geomorphological properties, it is an excellent study model for spatio-temporal dynamics of natural and anthropic activities. Based on photo-interpretation, aerial images of 1966 and 2013 were analyzed. Major changes in the environment, activities and land uses were described and confirmed by direct observation, reaching a complete description at the basin level. Native forests were characterized through a phyto-sociologic sampling design, and selected interviews were performed. An integrated discussion of these results was carried out considering regulation and planification of land for the region. Finally, major pressures by different land uses (urbanization, exotic species in forests, sewage input and dam at the water level) were identified. Integrative approaches at basin level with cualitative and cuantitative parameters allowed to identify pressures that can exert changes (reversible or not) towards an integrated management of the socioecosystems.

Keywords: Environmental management, photointepretation, phytosociology.
\end{abstract}




\section{Introducción}

Los cuerpos de agua son la base en los ambientes naturales. Por lo tanto, la cuenca es la base geográfica adecuada para una correcta gestión orientada a la conservación ambiental, manteniendo la calidad de vida de los seres humanos, que a su vez depende de la preservación de estos ambientes (Lin, et al., 1997). Se entiende por cuenca aquella superficie cuya escorrentía fluye por una red hidrográfica y que tiene una única salida a un cuerpo o curso de agua (Unión Europea, 2000). Como unidad de gestión presenta las ventajas de tener límites determinados por atributos ambientales y no político administrativos (Grumbine, 1994) y de integrar los distintos componentes bióticos y abióticos tomando como central el ciclo hidrológico (Lundqvist, et al., 1985). Abordando la gestión desde una perspectiva de cuenca se pueden observar las alteraciones en múltiples escalas espaciales (Allan, et al., 1997).

La gestión integrada de cuencas es un ejemplo de manejo ecosistémico cuyo abordaje vincula el conocimiento sobre relaciones ecológicas y el sistema social. Es una herramienta multiobjetiva que trasciende el manejo hidrológico y aporta a la conservación en general de suelos y aguas (Hooper, 2003). La gestión de cuencas implica un manejo adaptativo, ya que es necesario adoptar una postura de incertidumbre y aprendizaje permanente para tener flexibilidad en la gestión (Grumbine, 1994).

Desde hace varias décadas, en América Latina y el Caribe se ha implementado el manejo o gestión integrada de cuencas hidrográficas (Achkar, et al., 2004). Este concepto se origina en Estados Unidos en el año 1920 y su implementación comienza a ser masiva en la década de 1990 (Allan, et al., 1997; Unión Europea, 2000). A nivel nacional el manejo integrado de cuencas hidrográficas se desarrolla bajo la Ley de Política Nacional de Aguas No 18.610 (Uruguay, 2009). Esta ley que regula el uso sustentable del recurso y su protección determina que para su manejo se debe realizar una evaluación y planificación periódica del recurso hídrico, manteniendo una visión multidisciplinaria y multiobjetiva orientada a satisfacer necesidades y requerimientos de la sociedad en materia de agua. En Maldonado se encuentra vigente el Decreto Departamental No 3867 (Uruguay, 2010) que establece disposiciones de ordenamiento territorial y categorización del suelo, y promueve el manejo de bienes y recursos naturales y culturales, y la protección y valorización de las áreas naturales, rurales y urbanas.

La cuenca del Arroyo Tarariras está ubicada en la zona de transición de la vegetación costera entre la Litoral Platense y la Atlántica (Delfino, et al., 2011). A su vez, según la FEOW (Ecorregiones Dulceacuícolas del Mundo, por sus siglas en inglés), la cuenca se encuentra en el límite de dos ecorregiones dulceacuícolas: Paraná Inferior y Laguna Dos Patos. Según las unidades morfoestructurales propuestas por Panario et al. (2011), las ecozonas Sierras del Este y Graven de Santa Lucía se dividen en la zona. También las biozonas de peces y reptiles a nivel país presentan divisorias en este lugar (Brazeiro, et al., 2012).

El Cerro de los Burros y el Valle del Arroyo Tarariras conforman, además, una localidad arqueológica: presenta registro de ocupación humana desde hace aproximadamente 13.000 años (Meneghin, 2000; Politis, et al., 2004; Brum Bulanti, 2011). La zona integra la carta G-29 del Servicio Geográfico Militar que fue considerada como prioridad para el ingreso al Sistema Nacional de Áreas Protegidas (Soutullo, et al., 2010). Actualmente está ubicada en la categoría de ingreso condicional debido a la falta de información sobre la viabilidad desde los puntos de vista económico, social y político (Soutullo, et al., 2014).

Existen en la zona organizaciones civiles que nuclean residentes y veraneantes interesados y comprometidos con el cuidado y la preservación del área. Entre 2001 y 2014 se realizaron varias actividades por parte de estas organizaciones para difundir el valor patrimonial de la zona y promover su protección (Comisión de Vecinos Cerro de los Burros, 2013). Por acción de la comisión de vecinos se logró que el Cerro de los Burros se declarara Patrimonio Departamental, según Resolución No 04287/2013 de la Junta Departamental de Maldonado (Uruguay, 2013), y Monumento Histórico Nacional, según Resolución Nº 249/014 del Ministerio de Educación y Cultura (Uruguay, 2014). Las características naturales y patrimoniales de la microcuenca del Tarariras, junto con las presiones de actores locales, motivan la necesidad de implementar un sistema integrado de manejo que preserve su calidad.

El objetivo general de este trabajo es generar aportes para el manejo integrado de la cuenca del Arroyo Tarariras. Los objetivos específicos son determinar los cambios de cobertura del suelo en el tiempo, realizar la caracterización primaria de los bosques e identificar las presiones actuales y potenciales para la conservación de los ambientes y valores patrimoniales.

\section{Materiales y Métodos}

Se tomó la cuenca como unidad de estudio, integrando los distintos componentes físico-bióticos y humanos. La información se procesó en un Sistema de Información Geográfica (GvSIG versión 2.14) para identificar y categorizar los cambios en los usos y ambientes en el tiempo y las presiones asociadas. Se tomaron como base las imágenes del vuelo fotogramétrico de la Fuerza Aérea Uruguaya de 1966 y las más recientes que se disponían en Google Earth (2013).

El límite de la cuenca se determinó a partir de la modelación en el SIG, tomando como base las curvas de nivel disponibles en la Infraestructura de Datos Espaciales del Uruguay (IDE). Las imágenes del año 1966 fueron digitalizadas y georreferenciadas al SiG, mientras que las de Google Earth fueron cargadas directamente con las herramientas del programa. La identificación de elementos y categorías se realizó sobre la imagen en el SIG, siguiendo criterios de identificación visual (Chuvieco, 2006). Para sistematizar la información se usó un sistema de categorías adaptado de Álvarez et al. (2015), en el que cada porción del territorio fue asociada a una de ellas. Las categorías se agruparon en dos tipos: las áreas naturales (pradera arbustiva, pradera herbácea, bosques y afloramientos rocosos) y las áreas de usos y actividades (área urbana, cultivos agrícolas, montes frutales, montes de abrigo - 5 ha, plantaciones forestales + 5 ha y zona industrial). La observación directa en terreno permitió verificar la correcta asignación e identificar cambios que pudieran haber ocurrido entre 2013 y 2016. De las más de 3.131 hectáreas que tiene la cuenca, solo 71 $(2,3 \%)$ no fueron asignadas a una categoría y corresponden a la red vial y pequeños claros que por su resolución no pudieron ser minimizados.

Para una primera caracterización de los bosques de la cuenca se aplicó un muestreo de la diversidad florística. 
Se realizó una estratificación primaria siguiendo criterios geográficos (Prodan, et al., 1997) y a partir de la fotointerpretación de 2013 se utilizaron las categorías propuestas por Brussa y Grela (2007): ribereño, serrano, marítimo o psamófilo. El muestreo se realizó por el Método de Cuadrantes Centrados de Morisita (1957) modificado por Mitchell (2007). En la Tabla 1 se presentan los indicadores y su fórmula de cálculo. Se trazaron transectas perpendiculares al curso de agua debido al gradiente de especies en función del nivel de humedad (Piaggio y Delfino, 2009), determinando una zonificación microclimática (Brussa y Grela, 2007). En los parches de más de 10 hectáreas, correspondientes únicamente al bosque serrano, los puntos de muestreo se ubicaron cada 100 metros. Se tomaron transectas en la parte alta, media y más baja con respecto a la altitud. En los demás parches y para todos los tipos de bosque, los puntos de muestreo sobre la transecta se ubicaron cada 20 metros. Un total de 50 sitios fueron muestreados en toda la cuenca, en los tres tipos de bosque y con variantes en el tamaño de parche. Se realizaron cuatro transectas en bosque serrano, tres en bosque ribereño y una en bosque marítimo. Dentro de cada cuadrante se relevó el individuo más cercano al punto central de muestreo, registrando la distancia a este (distancia r) y el diámetro a la altura del pecho (DAP) del árbol. Como el objetivo era relevar la vegetación arbórea, se registraron todos los individuos de DAP mayor a $7 \mathrm{~cm}$.

Se realizaron entrevistas semiestructuradas a actores referentes de las diferentes localidades que involucra la cuenca, pertenecientes a organizaciones de la sociedad civil o gradualmente referidos por otros entrevistados como conocedores del área, según el sistema «bola de nieve» (Taylor y Bodgan, 1987). Con esta estrategia se procuró obtener información cualitativa de personas con relación histórica con el lugar, participación en organizaciones sociales locales y actividad en diferentes balnearios y zonas de la cuenca. Estos atributos los convierten en informantes calificados que pueden dar cuenta de los cambios en su entorno en una escala temporal y brindar información cualitativa de importancia (Tongco, 2007) que permite completar vacíos que deja la investigación tradicional (Batthyány, et al, 2011).

Las entrevistas indagaron en cuatro ejes temáticos: historia del lugar y recuerdos del entrevistado; aspectos naturales o paisajísticos destacados; cambios o modificaciones (tanto positivos como negativos) que ha observado en la zona, y amenazas o tendencias que incidan en la zona. Las entrevistas fueron coordinadas con los entrevistados informándoles del objetivo y encuadre en el proyecto. Las mismas fueron grabadas con el consentimiento de los involucrados. Los audios fueron desgrabados y transcriptos para su posterior lectura, análisis y procesamiento.

Se realizaron un total de siete entrevistas, que cubrieron las diferentes localidades involucradas en la cuenca y sus organizaciones de la sociedad civil más destacadas. En ellas se pudo recoger información que agregó datos relevantes a la caracterización socioecológica e histórica del lugar. Este enfoque no tuvo un fin exhaustivo sino exploratorio; mediante esta técnica se proponía incorporar datos útiles al proyecto y a la formulación de sus objetivos.

Se tomó el Modelo Presión, Estado, Respuesta desarrollado por la Organización para la Cooperación y el Desarrollo Económico (OECD, 1993) que permite integrar en un cuadro de síntesis los distintos factores de presión que reporta la bibliografía sobre el ambiente. Este análisis se remite a identificar presiones y posibles cambios de estado en la Cuenca del Arroyo Tarariras. Se tomó como referencia biliográfica un listado de presiones sobre los ambientes naturales presentes en la cuenca y el patrimonio (CLAES, 2008; Achkar, et al., 2012; Comisión de Vecinos Cerro de los Burros, 2014).

\section{Resultados}

En base a las curvas de nivel y la red hidrográfica se determinaron los límites de la cuenca para el Arroyo Tarariras, abarcando un área total de 3.131 hectáreas $\left(31,31 \mathrm{~km}^{2}\right)$. Se lograron identificar todas las categorías de cobertura de suelo para casi la totalidad de la superficie de la microcuenca (97,7\%). En general, tanto en 1966 como en 2013, la microcuenca presenta una cobertura rural de suelo predominante, caracterizado por praderas herbáceas y arbustivas. Estas praderas representan aproximadamente $2 / 3$ del total de la superficie. En la fotointerpretación de las imágenes del año 1966 se observaron principalmente los ambientes de praderas arbustivas, herbáceas y bosques, que cubren 77,6 \% del área

\begin{tabular}{|c|c|c|}
\hline Indicador & Fórmula & Descripción \\
\hline Dominancia absoluta por especie (DA) & $\begin{array}{l}\text { DA: dA x Área basal } \\
\text { Área basal }=\mathrm{ABj}=\left(\pi^{*} \mathrm{DAP} \wedge 2\right) / 4 \\
\mathrm{DAP}=\text { diámetro del árbol a la altura } \\
\text { del pecho }(1,30 \mathrm{mts})\end{array}$ & $\begin{array}{l}\text { Cobertura de una especie } \\
\text { por unidad de superficie }\end{array}$ \\
\hline Densidad absoluta (dA) & $\begin{array}{l}\mathrm{dA}=1 / \mathrm{r}^{\wedge} 2 \\
\mathrm{r}=\text { distancias de cada individuo al punto } \\
\text { central de la estación por transecta } / \mathrm{C} \\
\mathrm{C}=\text { total de cuadrantes con especie }\end{array}$ & $\begin{array}{l}\text { La densidad absoluta }(\mathrm{dA}) \text { se } \\
\text { define como el número de árboles } \\
\text { por unidad de área y se determina } \\
\text { a partir de la distancia media }(\mathrm{r})\end{array}$ \\
\hline Frecuencia absoluta $(\mathrm{Fj})$ & $\begin{array}{l}\mathrm{Fj}=(\mathrm{Ej} / \text { Etotal }) \star 100 \\
\mathrm{Ej}=\text { Estaciones en las que aparece la } \\
\text { especie } \mathrm{j} . \\
\text { Etotal }=\text { Estaciones totales en una } \\
\text { transecta }\end{array}$ & $\begin{array}{l}\text { La frecuencia absoluta }(\mathrm{Fj}) \text { se } \\
\text { refiere al porcentaje de aparición } \\
\text { de la especie en el total de } \\
\text { estaciones }\end{array}$ \\
\hline
\end{tabular}

Tabla 1. Indicadores fitosociológicos. Adaptado de Mitchell (2007). Dominancia absoluta (DA); Densidad absoluta (dA); Frecuencia absoluta (Fj). 
Leyenda

$\square$ Cuenca Ao Tarariras
Red Vial
Vía férrea
Red hidrográfica
1966
$\square$ Tajamares
$\square$ Plantación forestal (+5 has)
$\square$ Plantación forestal (bosques de abrigo, -5 has)
$\square$ Prutales
$\square$ Pradera herbácea
$\square$ Cultivos agristiva
$\square$ Bosque nativo
$\square$ Afloramiento rocoso
Zona industrial
Zona urbana
$\square$ Playa

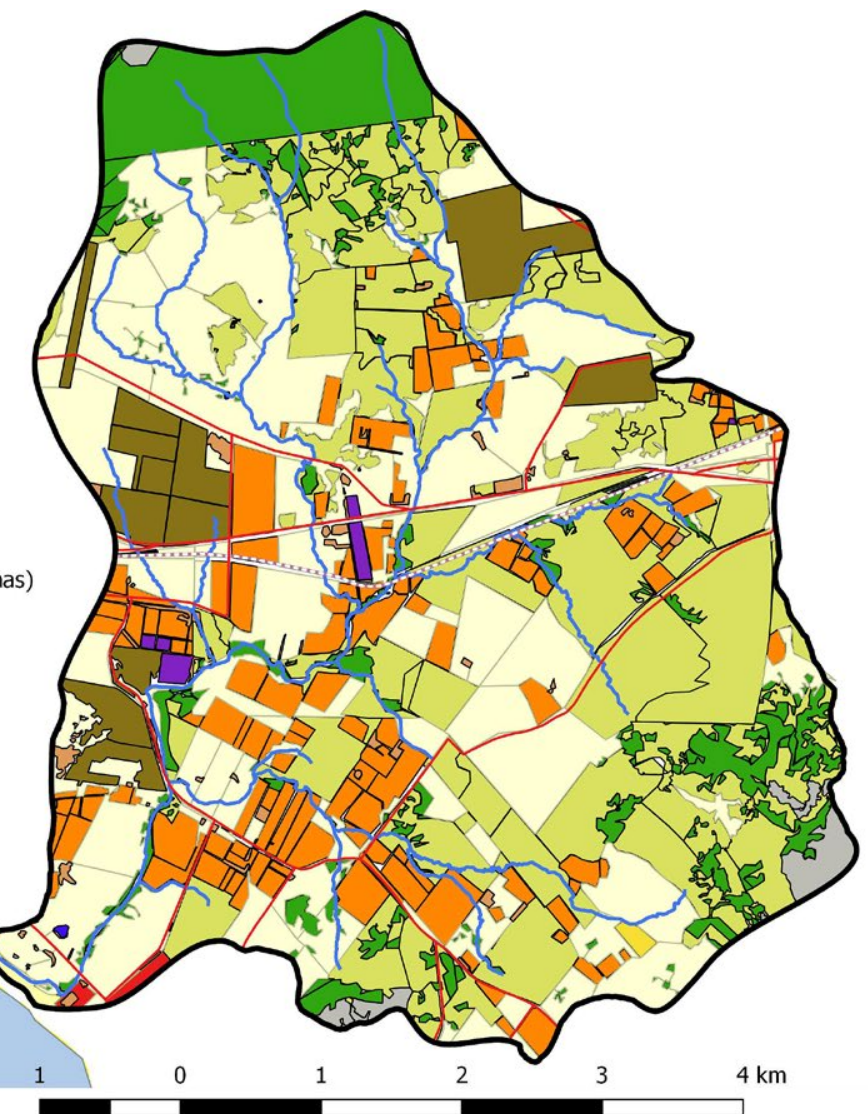

Figura 1. Mapeo de usos y ambientes en la Cuenca del Arroyo Tarariras, elaborado a partir de imágenes de 1966 de la Fuerza Aérea Uruguaya.

\section{Leyenda}

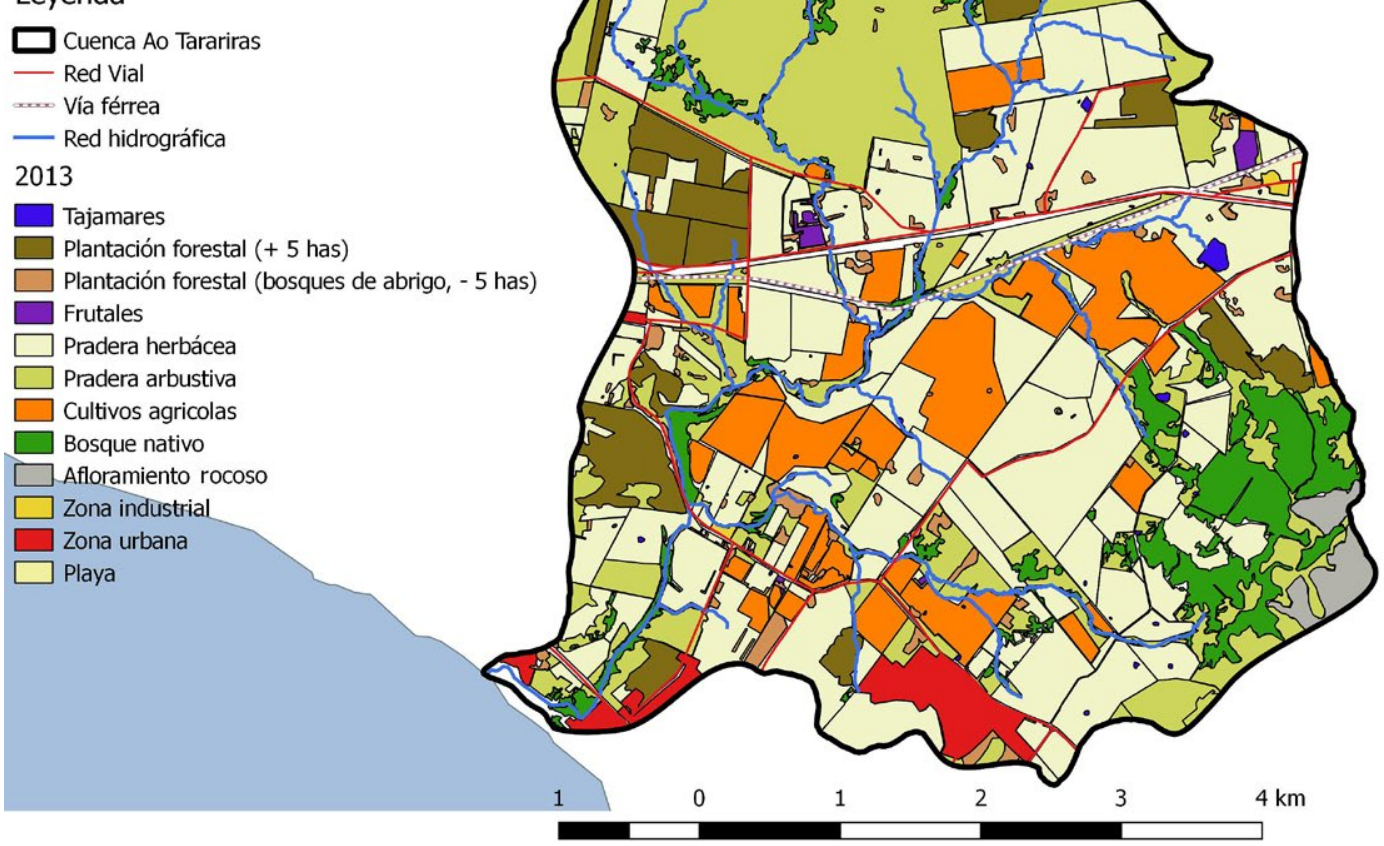

Figura 2. Mapeo de usos y ambientes en la Cuenca del Arroyo Tarariras, elaborado a partir de imágenes de 2013 de Google Earth. 


\begin{tabular}{|l|c|c|c|}
\hline Categoría & Área 1966 & Área 2013 & Cambio de cobertura (\%) \\
\hline Afloramiento rocoso & 36,62 & 39,12 & 7 \\
Bosque & 366,51 & 494,26 & 35 \\
Cultivos agrícolas & 388,08 & 312,36 & -20 \\
Frutales & 12,06 & 7,89 & -35 \\
Plantación forestal (+5 ha) & 181,94 & 215,13 & 18 \\
Plantación forestal (bosques de abrigo, -5 ha) & 32,55 & 62,17 & 91 \\
Pradera arbustiva & 974,8 & 738,63 & -24 \\
Pradera herbácea & 1051,75 & 1109,73 & 6 \\
Tajamares & 0,91 & 6,87 & 652 \\
Zona industrial & 3,78 & 3,40 & -10 \\
Zona urbana & 8,94 & 62,11 & 595 \\
\hline
\end{tabular}

Tabla 2. Análisis comparativo de áreas cubiertas por uso y ambiente para los dos años (1966-2013) en la Cuenca del arroyo Tarariras.

(Figura 1). En cuanto a los resultados de la fotointerpretación de imágenes de 2013, las praderas arbustivas, las herbáceas y el bosque mantienen la predominancia, aunque aumentó el área de cobertura de zona urbana, forestal y tajamares, que representa un $11 \%$ del área (Figura 2). Comparando estos resultados de fotointerpretación (1966-2013) se observa el área ocupada para cada categoría en cada serie y la variación existente; como mayores cambios se destacan los tajamares, los bosques de abrigo y la zona urbana (Tabla 2).

Por medio de la observación directa y entrevistas, se identificaron nuevas actividades: cultivos de olivos y chacras turísticas y de segunda residencia. Estas actividades emergentes se llevan a cabo en los mismos predios donde también se conservan parches de bosque nativo, muchos de ellos parquizados.

En los resultados fitosociológicos se aprecia que la diversidad de especies en los bosques muestreados fue variable (Figura 3). El bosque serrano (Sierra de las Ánimas) presentó el mayor grado de diversidad: 19 especies.

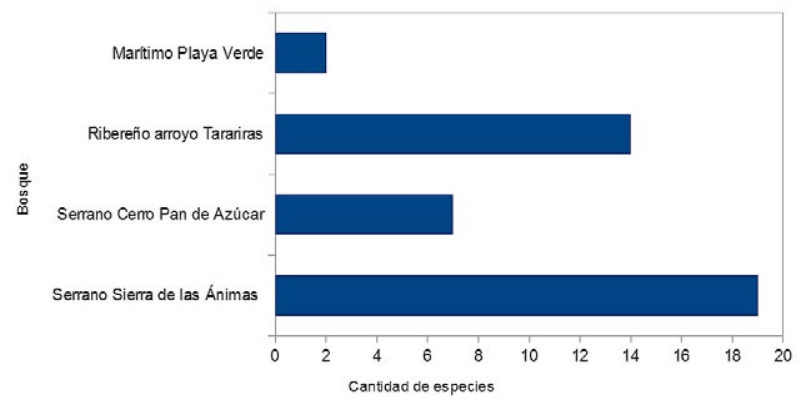

Figura 3. Diversidad de especies arbóreas por transecta y por tipo de bosque en la cuenca del arroyo Tarariras.

Las especies dominantes observadas en el total de los bosques muestreados de la cuenca fueron la aruera Lithraea brasiliensis y el chal-chal Allophylus edulis, con $25 \%$ de dominancia de cada especie en el total de las transectas (Figu-

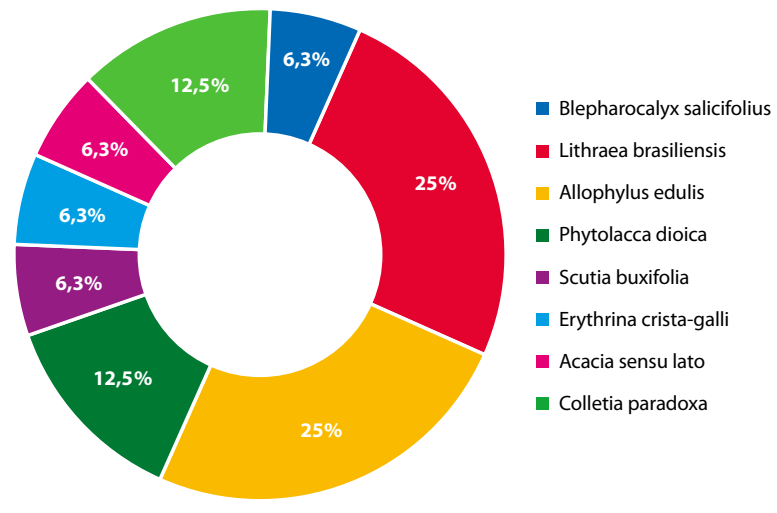

Figura 4. Especies dominantes en los bosques analizados de la cuenca del arroyo Tarariras.

ra 4). La observación cualitativa más importante fue la fuerte presencia de la especie exótica Ligustrum sp. que domina el sotobosque del bosque serrano con individuos de distinta altura. En los cuadrantes de los puntos de muestreo en el bosque ribereño no se encontraron exóticas. En cambio, el bosque marítimo está compuesto por la especie exótica Acacia sensu lato. Se registraron las especies arbustivas Dodonaea viscosa, Lantana camara y Bacharis tridentata, dado que alcanzaron el diámetro mínimo de $7 \mathrm{~cm}$.

Las entrevistas arrojaron información sobre los cambios en el área. En cuanto a las características del lugar, en el pasado se destacaban las zonas de pastizales y bosques, la fauna autóctona, la tranquilidad, las vistas a los cerros y los campos de pequeños productores en sus chacras. Al respecto de los cambios o modificaciones, se destacaron aquellos con mayor impacto visual, como las grandes construcciones, la forestación y la urbanización, así como aquellos que afectaron el modo de vida de los pobladores del área: la disminución de los productores familiares y pequeños establecimientos rurales, y la actividad comercial a pequeña escala. Estos productores locales abastecían a los veraneantes en temporada 
alta y a los pobladores residentes de la zona. Se mencionaron grandes establecimientos industriales en el área de la cuenca: el frigorífico y la planta procesadora de pescado.

En cuanto a las tendencias actuales, fue resaltado el aumento del turismo y la pérdida de cuencas visuales por forestación urbana o rural, la pérdida de vegetación nativa y de lugares de paseo (desembocadura del arroyo, cerros, playa), el aumento de basura y residuos.

De acuerdo al Modelo Presión, Estado, Respuesta (OECD, 1993), la principal presión identificada en la agricultura es el cambio del modelo productivo, asociado a monocultivos cerealeros o praderas artificiales con predios de mayor tamaño limitando la conectividad entre ambientes (Forman, 1995) Los insumos químicos que requiere tienen el potencial de alterar el suelo y el agua con nutrientes y contaminantes, afectando la dinámica de los ecosistemas (Tilman, 1999). El modelo forestal desarrollado implica especies exóticas de rápido crecimiento principalmente del género Eucalyptus, con el potencial de alterar el ciclo hidrológico reduciendo el escurrimiento superficial con respecto a la pradera (Silveira, et al., 2006).

\section{Discusión}

Los cambios en los cultivos agrícolas registrados mediante comparación de imágenes, entrevistas y observación directa muestran la concentración de la actividad en grandes parcelas. La situación en la cuenca de estudio no es diferente a la del resto de los territorios rurales de la Cuenca del Plata (Domínguez, et al., 2016). La demanda internacional de los denominados commodities ha cambiado el modelo productivo agrícola en Uruguay. Commodities son productos del sector primario con precios uniformes y posterior procesamiento, transados libremente en el mercado y sensibles a cambios significativos en los mercados en los que actúan (Consolandich, et al., 2011). Estos monocultivos y su extensión están asociados a la especulación en el mercado inmobiliario rural que lleva a que el paquete tecnológico de la agricultura moderna se base fuertemente en el uso de insumos externos, como fertilizantes y agroquímicos. Esto, a su vez, conduce a uno de los principales problemas actuales de Uruguay: la deriva de nutrientes y sustancias químicas a los cursos de agua (Bonilla, et al., 2015), los procesos de suba de precios y la concentración de la tierra (Domínguez el at., 2016).

En el ámbito rural ha aumentado la complejidad social y económica debido al ingreso de nuevos actores y actividades, muchas de ellas como extensiones de las ciudades (Gorenstein, et al., 2007). Lo rural como concepto ya no puede ser atado a la actividad agropecuaria sino, como refiere Pérez (2005), el espacio rural es sitio para diversas actividades económicas y sociales que trascienden la producción primaria. Como uno de los motores de cambio para el suelo rural, el turismo residencial ha impulsado la urbanización y los cambios en distintos ambientes, con posibilidades de grandes consumos hídricos y energéticos, además de la contaminación de ecosistemas, no solo en la zona donde se localiza, sino también a distancia (Aledo, 2008).

La diversificación de usos en la cuenca ha llevado a un mayor fraccionamiento y heterogeneidad en el paisaje, lo que constituye uno de los problemas mundiales en materia de biodiversidad (Kuusasaari, et al., 2009), que genera la división de hábitats y altera las funciones de los ecosistemas (Forman, 1995).
Es posible identificar numerosas chacras turísticas que apuntan a brindar un producto recreativo para un mercado que demanda el contacto con el entorno autóctono y el mantenimiento de la relación con la sociedad local (Valiente, et al., 2005).

En la cuenca se observan procesos de construcción paisajística que coinciden con otros realizados en el mundo, que implican la suplantación del paisaje cultural típico (Aledo, 2008). En este caso, chacras familiares, establecimientos lecheros y zona ganadera son suplantados por clubes de campo con paisaje artificial. Este tipo de fraccionamiento tiene más particularidades de urbano que de rural, y supone el desarrollo de importantes redes de caminería y la dotación de servicios. Esto implica un cambio de identidad y una desconexión del territorio con su cultura; la nueva identidad, promovida por estas formas de turismo residencial, tiene más contacto con un ambiente global que con los procesos y lugares de inmediata cercanía (Aledo, 2008). Mediante la observación directa y las entrevistas realizadas se percibió la inquietud de actores locales frente a este proceso y se verificó que existen predios rurales (clubes de campo) donde las actividades agropecuarias son un componente más de la oferta turística y no la actividad principal. Los proyectos inmobiliarios favorecen el traspaso de la propiedad de la tierra desde actores locales a inversionistas, muchos de ellos extranjeros, dando lugar a la «elitización» del territorio (Aledo, 2008; Aledo y Cañada, 2012). Esto genera presiones ambientales emergentes por los cambios radicales en el paisaje, como la instalación de cercos, elementos de seguridad y distintos tipos de barreras visuales (Thuillier, 2005).

Los resultados obtenidos muestran un crecimiento exponencial de la zona urbana en la franja costera. La zona presenta una población temprana, según Martínez Rovira (2002); ya en la segunda mitad del siglo XIX era posible encontrar poblaciones cerca del arroyo Tarariras. En las imágenes del año 1966 se identifican Estación y Balneario Las Flores, Playa Verde y zonas en proceso de urbanización conectadas por caminería local y rutas nacionales.

La urbanización sobre la franja costera ha crecido a impulso de la construcción de residencias para el turismo de sol y playa tradicional de la costa uruguaya (Arana, et al., 1983). Si bien esto ha sido medido por un proceso de ordenamiento territorial, sigue teniendo una debilidad en lo que respecta a la integración de variables ambientales. Hay urbanizaciones previstas para la margen del curso de agua y continúan las edificaciones en la zona de la desembocadura y en la planicie de inundación próxima.

La expansión del uso urbano implica impermeabilizaciones asociadas a las construcciones, nueva red vial y el ajardinado en base a flora exótica (Henry y Heinke, 1999), teniendo como consecuencia la alteración de la morfología costera por la fijación de dunas (CLAES, 2008).

La categorización de suelos aprobada por el gobierno departamental de Maldonado mediante el instrumento de ordenamiento territorial decreto $\mathrm{N}^{\circ} 3866$, Directrices Departamentales y Microregionales de Ordenamiento Territorial y Desarrollo Sostenible, (Uruguay, 2010) refuerza la posibilidad de cambio de rural a urbano en la franja costera, dado que presenta una importante porción del área con la categoría rural potencialmente transformable. La organización civil de vecinos del Cerro de los Burros reafirmó este acelerado incremento poblacional en la zona y consideró urgente la normativa pertinente para la conservación de los valores 
naturales y culturales del área (Comisión de Vecinos Cerro de los Burros, 2014).

Como principales cambios que afectan a los cursos de agua se identificaron el incremento del área de tajamares (652\%, Tabla 2), la construcción de dos pequeñas represas y la descarga del saneamiento de Pan de Azúcar. En particular, los tajamares pueden disminuir la calidad y cantidad del agua en el arroyo y presentar potenciales conflictos en sus usos como recurso común (Brito, et al., 2017). A su vez, las chacras de turismo rural representan una forma de suburbanización en la que se alteran los cuerpos de agua existentes o se crean nuevos con un fin paisajístico asociado a los procesos de parquización del entorno en las chacras y clubes de campo (Hernández, 2009).

El efluente doméstico que descarga en el arroyo Tarariras proviene de la planta de tratamiento primario de la ciudad de Pan de Azúcar con un caudal del efluente mayor al caudal natural del arroyo en el punto de descarga. OSE informó que en el año 2012 existían 1870 conexiones al saneamiento que derivan en esta planta y el efluente tratado que se descarga representa un flujo de $1300 \mathrm{~m}^{3} /$ día (OSE, 2016). El sistema de tratamiento actual implica lodos activados en modalidad de aireación extendida, con posterior desinfección por cloración, sin remoción de nutrientes.

La composición del bosque serrano descripto en este trabajo es similar a la consignada por Brussa y Grela (2007) para estos ecosistemas. En el caso del bosque ribereño del arroyo Tarariras, solo el Ceibo, Erythrina crista-galli, especie más característica y abundante, coincide con la lista de Brussa y Grela (2007). Las especies registradas e identificadas en el bosque ribereño en la zona de la cuenca del arroyo Tarariras, no mencionadas en la bibliografía, fueron: Celtis iguanaea, Colletia paradoxa, Eugenia uniflora, Jodina rhombifolia, Lantana, Phytolacca dioica, Schinus engleri y Trixis praestans.

En el bosque psamófilo solo se registraron dos especies, una exótica, Acacia sensu lato, y otra nativa, Colletia paradoxa. Se constató la ausencia de bosque en la zona costera de la cuenca y una fuerte presencia de especies exóticas. La ausencia de este tipo de bosque puede deberse a la fragmentación y transformación que ha sufrido la franja costera con el transcurso del tiempo. De hecho, el desarrollo turístico clásico en la costa platense y oceánica ha afectado de manera drástica a la flora nativa asociada (Alonso y Bassagoda, 1999).

Las invasiones de especies exóticas en la cuenca, que tienen origen en la interacción urbano-rural y cuyo fin inicial fue ornamental, hoy compiten y suplantan a las especies de los ecosistemas naturales y constituyen uno de los problemas ambientales más importantes en el ámbito terrestre (Lowe, 2000; Rands, et al., 2010), y a nivel país (CLAES, 2008; Aber, et al., 2014) ha sido verificado como una fuente de presión para la cuenca.

El decreto departamental $N^{\circ} 3866$ (Uruguay, 2010) hace referencia a que se elaborarán planes de gestión de nacientes con el objetivo de proteger los recursos hídricos mediante la conservación del bosque nativo asociado. En esta línea también se observa un choque de intereses, ya que existen normativas que apuntan en distintos sentidos, unas nacionales y otras departamentales. Por un lado, la zona de sierras se conforma por suelos que por la categorización CONEAT tienen baja productividad ganadera-agrícola, y ello llevó a incorporarlos al listado de suelos de prioridad forestal según el decreto nacional 220/2010 (Uruguay, 2010), que se realiza bajo un modelo productivo basado en especies exóticas de rápido crecimiento (Cannell, 1999). En contraposición, la ley
18308 de Ordenamiento Territorial y Desarrollo Sostenible promueve la protección de las nacientes de cursos de aguas y zonas altas, adjudicándoles prioridad ambiental. Se entiende que esta prioridad será ejecutada mediante los instrumentos de ordenamiento territorial desarrollados a nivel nacional o departamental. No se encontró normativa específica ambiental para la protección de la zona alta, que debía ser elaborada según se refiere en el decreto departamental $\mathrm{N}^{\circ}$ 3866 (Uruguay, 2010) .

Las aproximaciones integradas de diversas fuentes de información y a una escala espacial pequeña permiten identificar los cambios en la cobertura del suelo en el tiempo y espacio. Al asociarlos a la variación en las actividades antrópicas y sus efectos, permite mejores prácticas y prever tendencias. Esto representa un insumo clave para una correcta gestión de la cuenca y su preservación.

\section{Reconocimientos}

A Eduardo Marchesi, Patricia Mai, Matías Arim y Verónica Pinelli por el apoyo al proyecto. A los vecinos entrevistados, Lía Rodríguez, Marta Vila, Mirta Denis, Milton Casales, Graciela Linares y Aída Calveti. A Fabián Gómez de UGDOSE. A Andrés Linares, Betina Amorín y Micaela Amarillo. A Rina Diaz y Alejandra Escriva. A Roberto Díaz por abrirnos la puerta de su casa, compartir sus experiencias y acompañarnos en las salidas. A los estudiantes y docentes de UTU Arrayanes por integrarnos en actividades de intercambios en base a estudios en la zona.

\section{Referencias}

Aber, A., Ferrari, G., Zerbino, E., Porcile, J. F., Brugnoli, E., y Nuñez, L., 2014. Especies exóticas invasoras en el Uruguay. Montevideo: Comité Nacional de Especies Exóticas Invasoras. ISBN: 978-9974-658-02-8

Achkar, M. Cayssials, R. Domínguez, A. y Pesce, F., 2004. Hacia un Uruguay sustentable: gestión integrada de cuencas hidrográficas. Montevideo: Redes - AT.

Achkar, M., Brazeiro, A. y Bartesaghi. L., 2012. Principales amenazas para la conservación de la biodiversidad de Uruguay. Montevideo: MGAP/PPR; Facultad de Ciencias; Vida Silvestre; Sociedad Zoológica del Uruguay; CIEDUR.

Aledo, A. y Cañada, E., 2012. El turismo residencial en tiempos de crisis: ¿fin de un modelo? Barcelona: Icaria Editorial.

Aledo Tur, A., 2008. De la tierra al suelo: la transformación del paisaje y el nuevo turismo residencial. En: Arbor, 184(729), pp.99-113.

Allan, D., Erickson, D. y Fay, J., 1997. The influence of catchment land use on stream integrity across multiple spatial scales. En: Freshwater biology, 37(1), pp.149-161.

Alonso Paz, E. y Bassagoda, M. J., 1999. Los bosques y los matorrales psamófilos en el litoral platense y atlántico del Uruguay. En: Comunicaciones Botánicas del Museo de Historia Natural de Montevideo, VI(113), pp.1-8.

Álvarez, A, Blum, A y Gallego, F., eds., 2015. Atlas de cobertura del suelo del Uruguay. Montevideo: DINOT; FAO.

Arana, M., 1983. Paisaje y medio ambiente: algunas consideraciones sobre las áreas costeras en el Uruguay. En: Arana, M., Brailovsky, E., Bugnicourt, J., Gross, P, Favaro, E., Morello J., Presci, R., y Prudkin, N., Rieti, 
S., Sejenovich, H., Sunkel, Veiga D., y Villamil. J., eds. Medio ambiente y turismo. Buenos Aires: Consejo Latinoamericano de Ciencias Sociales. pp.123-151.

Batthyány, K., Cabrera, M., Alesina, L., Bertoni, M., Mascheroni, P., Moreira, N., y Rojo, V., 2011. Metodología de la investigación para las ciencias sociales: apuntes para un curso inicial. Montevideo: UdelaR.

Bonilla, S., Haakonsson, S., Somma, A., Gravier, A., Britos, A., Vidal, L., De León, L., Brena, B., Pírez, M., Piccini, C., Martínez de la Escalera, G., Chalar, G., González-Piana, M., Martigani, F., y Aubriot L., 2015. Cianobacterias y cianotoxinas en ecosistemas límnicos de Uruguay. En: INNOTEC, 10, pp.9-22.

Brazeiro A., Panario D., Soutullo A., Gutiérrez O., Segura A. y Mai P., 2012. Clasificación y delimitación de las eco-regiones de Uruguay: Informe Técnico. Montevideo; MGAP/PPR; Facultad de Ciencias; Vida Silvestre; Sociedad Zoológica del Uruguay; CIEDUR.

Brito, M., Pasquariello, S. y Tarragó, V., 2017. Aportes al diagnóstico de la calidad del agua de la Cuenca del Arroyo Tarariras. Maldonado: UdelaR.

Brum Bulanti, L., 2011. Ocupaciones litorales en las costas platenses del departamento Maldonado (Uruguay): Primeras aproximaciones. En: Revista de Estudios Marítimos y Sociales, 4(4), pp.21-30.

Brussa, C. A. y Grela, I., ed., 2007. Flora arbórea del Uruguay con énfasis en las especies de Rivera y Tacuarembó. Montevideo: COFUSA.

Cannell, M. G., 1999. Environmental impacts of forest monocultures: water use, acidification, wildlife conservation, and carbon storage. En: New Forests, 17(13), pp.239-262.

Chuvieco, E., ed., 2006. Fundamentos de teledetección espacial. Madrid: Ediciones Rialp.

CLAES, PNUMA y Uruguay. Ministerio de Vivienda, Ordenamiento Territorial y Medio Ambiente. Dirección Nacional de Medio Ambiente, 2008. GEO Uruguay, 2008: informe del estado del ambiente. Montevideo: Mosca.

Comisión de Vecinos Cerro de los Burros, 2013. Documentos que acompañan la solicitud de protección de la localidad arqueológica del Cerro de los Burros. Tarariras.(Inédito).

Comisión de Vecinos Cerro de los Burros, 2014. Propuesta de ingreso del Cerro de los Burros al Sistema Nacional de Áreas. (Inédito).

Consolandich, G., Ferreira, P. y Fierro, L., 2011. Índice de precios de exportaciones agropecuarias (1999-2009). Construcción de un índice con precios de referencia internacional para las principales exportaciones agropecuarias de Uruguay. Montevideo: Facultad de Ciencias Económicas y de Administración.

Delfino, L., Piñeiro, V., Mai, P., Mourelle, D., Garay, A. y Guido, A., 2011. Florística y fitosociología del bosque psamófilo en tres sectores de la costa de Uruguay, a lo largo del gradiente fluvio-marino. En: Iheringia, 66 (2), pp.175-188.

Domínguez, A., Achkar, M. y Pesce, F., 2016. Dinámicas espaciales, transformaciones territoriales y nuevas regionalidades en el Uruguay rural contemporáneo. En: Asociación de Universidades del Grupo de Montevideo. XI Bienal del Coloquio de Transformaciones Territoriales. Salto, Uruguay. (27-29 de Julio de 2016) Montevideo: Asociación de Universidades del Grupo de Montevideo.
Forman, R. T., 1995. Land Mosaics: The Ecology of Landscapes and Regions. Cambridge: Cambridge University Press.

Gorenstein, S., Napal, M. y Olea, M., 2007. Territorios agrarios y realidades rururbanas: Reflexiones sobre el desarrollo rural a partir del caso pampeano bonaerense. En: Eure. 33(100), pp.91-113.

Grumbine, R. E., 1994. What is ecosystem management? En: Conservation biology, 8(1), pp.27-38.

Henry, J. G. y Heinke, G. W., 1999. Ingeniería ambiental. 2a ed. México: Pearson Educación. ISBN 0-13-120650-8

Hernández, F., 2009. Urbanizaciones privadas en América Latina, los 'guetos' del siglo XXI: el caso del crecimiento de countries y barrios privados en la costa atlántica argentina: En: XII Encuentro de geógrafos de América Latina. Caminando en una América Latina en Transformación. Montevideo (3-7 de abril de 2009). Montevideo: [s.n.]

Hooper, B. P., 2003. Integrated water resources management and river basin governance. En: Water Resources Update, 126(1), pp.12-20.

Kuusasaari, M., Bommarco, R., Heikkinen, R. K., Helm, A., Krauss, J., Lindborg, R. y Stefanescu, C., 2009. Extinction debt: a challenge for biodiversity conservation. En: Trends in Ecology \& Evolution, 24(10), pp.564-571.

Lin, T. L., Byrne, J., Mainhart, K., Ramakrishna, V., Chen, Y., Sylves, R. T. y Pfeufer, A. C., 1997. Whole basin management: policy implications for delaware. Delaware: Center for Energy and Environmental Policy

Lowe, S., Browne, M., Boudjelas, S. y De Poorter, M., 2000. 100 of the world's worst invasive alien species: a selection from the global invasive species database. Auckland: ISSG.

Lundqvist, J., Lohm, U. y Falkenmark, M., eds., 1985. Strategies for river basin management: environmental integration of land and water in a river basin. Vol. 6. Dodrechet: Springer Science \& Business Media.

Martínez Rovira, E., 2002. A pie y a caballo. 2a. ed. Montevideo: AMDG Ediciones.

Meneghin U., 2000. Artefactos líticos elaborados por picado y abrasión del Cerro de los Burros (Yacimiento II), Uruguay. En: Comunicaciones Antropológicas del Museo de Historia Natural de Montevideo, 2(20), pp.1-24.

Mitchell, K., 2007. Quantitative analysis by the point-centered quarter method. [Consulta 7 de julio de 2016] Disponible en: https://arxiv.org/abs/1010.3303

Organisation for Economic Co-operation and Development, 1993. OECD Environmental Indicators. Development, Measurement and Use. Paris: OECD

Pérez, E., 2005. Desafíos sociales de las transformaciones del mundo rural: nueva ruralidad y exclusión social. En: Chile rural: un desafío para el desarrollo humano. [s.l.]: PNUD; Gobierno de Chile. pp.17-32.

Piaggio, M. y Delfino, L., 2009. Florística y fitosociología de un bosque fluvial en Minas de Corrales, Rivera, Uruguay. En: Iheringia, 64, pp.45-51. (Série Botânica)

Politis, G.G., Messineo, P.G. y Kaufmann, C. A., 2004. El poblamiento temprano de las llanuras pampeanas de Argentina y Uruguay. En: Complutum, 15, pp.207-224.

Prodan, M., Peters, R., Cox, F. y Real, F., ed., 1997. Mensura Forestal. San José: GTZ; IICA. (Serie Investigación y Educación en Desarrollo Sostenible).

Rands, M. R., Adams, W. M., Bennun, L., Butchart, S. H., Clements, A., Coomes, D. y Sutherland, W. J., 2010. Biodiversity conservation: challenges beyond 2010. En: Science, 329(5997), pp.1298-1303. 
Silveira, L., Alonso, J. y Martínez, L., 2006. Efecto de las plantaciones forestales sobre el recurso agua en el Uruguay. En: Agrociencia, 10(2), pp.75-93.

Soutullo, A., Bartesaghi, L., Berazategui, P., Clavijo, C., Díaz, I., Faccio, C. y González, E. M., 2010. Diseño espacial del Sistema Nacional de Áreas Protegidas de Uruguay: sitios a ingresar al sistema, prioridades de conservación en esos sitios y aportes a la protección de la biodiversidad fuera de áreas protegidas. Montevideo: MVOTMA; PNUD/GEF.

Soutullo A., Bartesaghi L., Ríos M., Szephegyi M.N. y Di Minin E., 2014. Prioridades espaciales para la expansión y consolidación del SNAP en el período 2015-2020. Montevideo: MVOTMA; PNUD.

Taylor, S. J. y Bodgan, R., 1987. Introducción a los métodos cualitativos de investigación. Barcelona: Paidós Ibérica. ISBN: 84-7509-816-9

Tongco, M. D. C., 2007. Purposive Sampling as a Tool for Informant Selection. En: Ethnobotany Research \& Applications, 5, 147-158.

Thuillier, G., 2005. El impacto socio-espacial de las urbanizaciones cerradas: el caso de la Región Metropolitana de Buenos Aires. En: Eure, 31(93), pp.5-20.

Tilman, D., 1999. Global environmental impacts of agricultural expansion: the need for sustainable and efficient practices. En: Proceedings of the National Academy of Sciences, 96(11), pp.5995-6000.
Unión Europea, 2000. Directiva 2000/60/CE de 23 de octubre de 2000. Diario Oficial, $\mathrm{N}^{\circ}$ L 327 de 22/12/2000 pp.1-73.

Uruguay. Decreto 249/014, de 26 de agosto de 2014. Diario Oficial, 3 de setiembre de 2014, No. 29.038, pp. 6-8

Uruguay. Decreto 220/010, de 14 de julio de 2010. Diario Oficial, 29 de julio de 2010, No. 28.027, p.211A.

Uruguay. Junta Departamental de Maldonado. Decreto 3866, de 27 de abril de 2010. Libro de sesiones XLVI (III), pp.3451-3458.

Uruguay. Junta Departamental de Maldonado. Decreto 3867 de 27 de abril de 2010. Libro de sesiones XLVI (III), pp.3464-3477.

Uruguay. Ley de Ordenamiento Territorial y Desarrollo Sostenible $\mathrm{N}^{\circ} 18.308$ de 18 de junio de 2008. Diario Oficial, 30 de junio de 2008. p.1420.

Uruguay. Ley 18.610, de 2 de octubre de 2009. Diario Oficial, 28 de octubre de 2009. p.333A.

Uruguay. Junta Departamental de Maldonado. Resolución 04287 de 12 de junio de 2013. Acta No. 01269/2013.

Uruguay. Resolución 87/016. OSE. Informe sobre la situación de los efluentes de Pan de Azúcar a partir de solicitud de acceso a la información pública.

Valiente, G. C., Jiménez, L. H., y Pérez, M. V., 2005. Turismo rural en España: paisajes y usuarios, nuevos usos y nuevas visiones. En: Cuadernos de turismo, 2005(15), pp.63-76. 